\title{
Quantitative Evaluation of the Facial Morphology of a Tolteca Figurine from Mexico using Geometric Morphometric Approaches
}

\author{
Evaluación Cuantitativa de la Morfología Facial de una Figura \\ Tolteca de México Utilizando la Morfometría Geométrica
}

John M. Starbuck*

STARBUCK, J. M. Quantitative evaluation of the facial morphology of a Tolteca figurine from Mexico using geometric morphometric approaches. Int. J. Morphol., 32(2):499-509, 2014.

SUMMARY: Morphometric approaches can be combined with 2D or 3D imaging to quantitatively evaluate craniofacial medical conditions depicted in material culture and to learn more about the culture being studied. A terra-cotta figurine (circa 500 A.D.) from the Tolteca culture of Mexico has previously been qualitatively "diagnosed" with Down syndrome (DS) based on the presence or absence of facial features typically associated with trisomy 21 . The purpose of this research is to quantitatively test the hypothesis that the Tolteca figurine exhibits facial features consistent with DS. Landmarks $(n=24)$ were acquired from sex- and age-matched $(5-20$ yrs $)$ facial images of DS individuals $(n=32)$, euploid individuals $(n=32)$, and the Tolteca figurine. Landmark coordinates were subjected to geometric morphometric analyses, and the results suggest that the Tolteca figurine displays facial morphology consistent with DS. analysis.

KEY WORDS: Trisomy 21; Down syndrome; 3dMD; Euclidean distance matrix analysis (EDMA); Principal coordinates

\section{INTRODUCTION}

The range of variation in facial features of contemporary humans, non-human primates, and purported human ancestors has long held the interest of anthropologists, biologists, and anatomists. Developmental perturbations are capable of altering the typical human facial blueprint to create facial phenotypes that may be diagnostic of particular environmental or genetic effects. Developmental conditions that affect the craniofacial complex have historically been depicted in artwork, and many congenital abnormalities and genetic disorders can be diagnosed in material culture to learn more about a particular culture and the evolution of the medical condition being investigated (Canalis \& Cino, 2003; Emery, 1996; Pirsig et al., 1995; Salter \& Ramachandran, 2008; Vegter \& Hage, 2000).

Down syndrome (DS) results from having three copies of chromosome 21 (i.e. trisomy 21) and occurs at a frequency of about 1:700 across the world (CDCP, 2006; Kuppermann et al., 2006; LeJeune et al., 1959). Today the average lifespan of individuals with DS is more than 50 years, but in 1900 the average DS lifespan was only 9 years
(Collmann \& Stoller, 1963; Megarbane et al., 2009). Individuals with DS typically display characteristic facial morphology and impaired cognition (Richtsmeier et al., 2000). A constellation of other traits may be associated with DS faces including: almond-shaped eyes, epicanthic folds (Oliver, 1891; Shuttleworth, 1886), a flat or depressed nasal bridge and upturned nose (Greig, 1927a, 1927b; Jones, 1890), midfacial hypoplasia (Frostad et al., 1971; Kisling, 1966), an open-mouthed facial posture that may include a protruding tongue, and reduced rates of craniofacial growth (Benda, 1941; O'Riordan \& Walker, 1979). Different combinations of DS facial traits may be present in each individual DS face because of allelic variation, ancestral background, and variable levels of gene expression due to copy number variation and gene-dosage imbalance caused by trisomy 21 (Ionita-Laza et al., 2009; Korbel et al., 2009; Makino \& McLysaght, 2010). Other factors that affect facial appearance include inter- and intra-population differences, sex, and age. As a result of these influences, DS individuals tend to resemble each other, but often also resemble their family members (Shaner et al., 2001). 
Skeletal remains with phenotypic features consistent with DS have been dated to 5200 B.C., but DS has likely occurred throughout human existence (Walker et al., 1991). Possible depictions of DS in historical material culture are dated as far back as 5000 B.C. (Diamandopoulos et al., 1997) and can be found in several figurines, ceramic pottery, and paintings (Starbuck, 2011). Diagnoses of the presence or absence of DS in artifacts are often evaluated in a qualitative and subjective manner based on the presence or absence of traits associated with trisomy 21 (Starbuck, 2011).

Martinez-Frias (2005) published a photograph of a terra-cotta figurine (circa 500 A.D.) from the Tolteca culture of Mexico that may exhibit DS. The author argued that the terra-cotta figurine exhibits short palpebral fissures, oblique eyes, midfacial hypoplasia, and an open mouth with a protruding tongue (Fig. 1) (Martinez-Frias). The individual depicted in the Tolteca figurine also appears to be wearing a headpiece and an earring, possibly with a stretched earlobe.

Although the Tolteca figurine appears to be a child with DS, quantitative evidence of this diagnosis is lacking. The purpose of this investigation is to use geometric morphometric methods to quantitatively compare the facial morphology of the Tolteca figurine to DS and euploid samples. It is hypothesized that the facial morphology exhibited by the Tolteca figurine will be more consistent with the range of facial morphology associated with DS, and less consistent with the range of facial morphology associated with euploid individuals.

\section{MATERIAL AND METHOD}

Facial 3D surface images. Age-matched (5-20 yrs) 3D surface images of DS individuals $(\mathrm{n}=32)$ and euploid individuals $(\mathrm{n}=$ 32) were obtained with the 3dMD face system (http:// $3 \mathrm{dmd} . \mathrm{com} /$ ). Subjects were instructed to display a neutral facial expression while sitting upright. The 3dMD system acquires multiple images of the same individual simultaneously and uses a random point cloud to merge $2 \mathrm{D}$ images into a single 3D facial image that represents facial topography.

A wide age-range was chosen for each sample because the age of the individual depicted by the Tolteca figurine is unknown. Because the sex of the Tolteca figurine is also unknown, a male and a female for each particular age were chosen for each sample. Individuals from various ethnic backgrounds were included in each sample (i.e. Caucasian, Hispanic, Asian, African-American, Native American) to establish the range of facial variation present across DS and euploid individuals.
Standardizing 3D image orientation. Because a 3D image of the Tolteca figurine was unobtainable, the orientation of 3D surface images of DS and euploid individuals were standardized to the same orientation depicted in the Tolteca figurine, and 3D images were saved in 2D (JPEG) for morphometric analysis. The angle between 2 lines $\left(88.3^{\circ}\right)$ drawn through left and right endocanthion (i.e. len-ren) and nasion and labrale superius (i.e. n-ls) was measured on the Tolteca figurine image using a 7" iGaging digital protractor $\&$ ruler (reported measuring range $0-360^{\circ}$, resolution $0.05^{\circ}$, accuracy $\pm 0.2^{\circ}$, and repeatability $\left.0.1^{\circ}\right)$, and this angle was subsequently verified using ImageJ software (http:// rsbweb.nih.gov/ij/download.html). Next, each individual 3D image was oriented into the same position as the Tolteca figurine, and the angle between len-ren and n-ls was measured to standardize orientation between the figurine, DS, and euploid samples. Orientation for each 3D image was considered accurate once the angle between len-ren and $\mathrm{n}-1 \mathrm{~s}$ was within $88.3^{\circ} \pm 1.5^{\circ}$. DS and euploid 3D images were saved in 2D (JPEG), and the measurement of this angle was verified in ImageJ for each image.

Data Collection and exploration. Facial landmarks and assessment of error. A large number of quantitative geometric morphometric methods (e.g. Procrustes superimposition, Euclidean Distance Matrix Analysis) exist for measuring and comparing morphological form (Richtsmeier et al., 2002). The use of landmarks in geometric morphometric research has become widespread because landmarks are repeatable and provide geometric information in terms of the relative location of structure (Bookstein, 1991; Lele \& Richtsmeier, 2001). Using ImageJ software 24 landmarks (Table I, Fig. 2 ) were located and landmark coordinate values were recorded for analysis. A subset of 5 images was chosen to assess measurement error. Landmarks were located and x, y coordinates recorded for each image on 3 separate occasions with at least 24 hours between landmarking trials to avoid memory bias in landmark placement. The standard deviation among homologous $\mathrm{x}$ and y landmark coordinates was calculated for each of the 5 images measured. The mean standard deviation among all images was then calculated to assess measurement error $($ mean $=0.58 \mathrm{~mm}, \mathrm{x}=0.59, \mathrm{y}=$ 0.57 ) and is considered adequately low for the purposes of this study. Following assessment of measurement error coordinate values for 24 landmarks were collected and recorded from each facial image and used in analysis.

Outliers. Landmark coordinate data were explored in MorphoJ using the outlier option to view how each individual's landmark coordinates deviate from the average landmark configuration and to ensure that no landmark labels had been swapped during data collection (Klingenberg, 2011). No individuals were removed as outliers. 
Allometry. Allometry is morphological variation that is related to size variation (Klingenberg, 2009; Mitteroecker \& Bookstein, 2007). The concept of allometry refers to changes in the proportions of parts of the body that become altered as an organism ages. Centroid size is defined as the square root of the sum of the squared distances of all landmarks from their centroid and is a measure of the amount of dispersion of the landmarks around their centroid (Bookstein, 1996). Landmark coordinate data were initially assessed for the presence of allometry in MorphoJ software by regressing individuals upon their centroid size and then testing for allometry using residual permutation $(10,000$ rounds) (Klingenberg, 2011). The amount of shape variation explained by allometry was low (2.48\%), not significant (pvalue $=0.1142$ ), and therefore an allometric correction was unnecessary.

Morphometric Analyses of Facial Form. Procrustes superimposition. Landmark coordinates were subjected to a generalized Procrustes superimposition in MorphoJ (Klingenberg, 2011) to minimize the influence of size following methods described by Klingenberg \& McIntyre (1998). An overall best fit of landmarks was achieved by rescaling landmark configurations to a standard size, shifting them to a standard position using centroid superimposition, and rotating them to a standard orientation in iterations using a least squares criterion that minimizes the sum of squared distances among homologous landmarks (Klingenberg, 2002; Klingenberg et al., 2002; Leamy \& Klingenberg, 2005). These steps do not change the shape information contained within the landmark data, and an average consensus configuration of landmarks is created that represents shape variation among samples.

Principal Components Analysis. Morphological variation of Procrustes superimposed facial landmark coordinates was explored by generating a covariance matrix and carrying out a Principal Components Analysis (PCA) following methods described by Klingenberg et al. (2002). PCA is typically used as a data reduction ordination method to explore patterns of variation in multivariate shape-space for multiple variables within a sample (Klingenberg \& McIntyre). Here PCA confidence ellipses were used to determine if the pattern of morphological variation present in the face of the Tolteca figurine is more consistent with patterns of morphological variation present in the DS sample or the euploid sample. PCA does not rely on a priori knowledge of a sample's group structure. Therefore, it stands to reason that if the Tolteca figurine exhibits patterns of facial morphology more consistent with the DS sample then the figurine should cluster more closely to the DS sample and further away from the euploid sample.
PCA transforms the variables being analyzed into a new set of variables called principle components (PCs), which are uncorrelated and orthogonal to each other and can be inspected and interpreted separately. Each PC accounts for a percentage of the variance in data, and the order of the PCs successively accounts for the maximum possible amount of variation (Klingenberg, 2002; Klingenberg et al., 2002). The sum of all PCs explains all the variance in the data. To accomplish transformation of variables into PCs the PCA defines a new coordinate system that is aligned with the main axes explaining variation in the shapespace defined by the morphometric data. The variance associated with each PC is called an eigenvalue. The PCs and associated eigenvalues characterize the directions and amounts of multivariate variation in a sample (Klingenberg, 2002). Typically, the first three PCs provide the best approximation of the total variation in the data being explored and shape variation associated with each PC can be explored using wireframe graphs (Klingenberg, 2011; Klingenberg \& McIntyre).

Euclidean Distance Matrix Analysis global form test. Alternative means for assessing facial variation were also carried out to determine if additional geometric morphometric methods provide similar answers. A 2-sample Euclidean Distance Matrix Analysis (EDMA) approach was used to statistically test for similarity in facial form among samples following the methods of Lele \& Richtsmeier. EDMA is a coordinate system invariant method that does not rely on translation, rotation, or reflection of the samples being studied. Anatomical landmark coordinates were scaled by the geometric mean to correct for potential size differences among images and coordinate data were converted into a form matrix, consisting of all unique linear distances among landmarks ( $\mathrm{n}=276$ for each image). Mean form matrices consisting of average linear distance measures between samples were compared using a nonparametric bootstrap $(10,000$ resamples) to assess global form similarity, and a pvalue of $\leq 0.05$ was considered significant. The following 2-sample comparisons were carried out to assess the null hypothesis of similarity in global facial form: 1) figurine compared to DS sample, 2) figurine compared to euploid sample, and 3) DS sample compared to euploid sample.

Principal coordinates analysis. Additionally, an extension of the EDMA approach called a principal coordinates analysis (PCOORD) was applied to the 3 samples following the methods described by Richtsmeier et al. (1998). PCOORD explores the specific combinations of linear measurements that best separate samples in multidimensional form space by assessing dissimilarity among every possible pair of individuals and compiling dissimilarity values into a matrix that is subjected to an eigenanalysis to obtain 
eigenvalues and eigenvectors for each individual (Richtsmeier et al., 1998). The result is an ordination of the individuals on the basis of the original landmark data that is projected into multivariate form space (Richtsmeier \& Lele, 1993). Similar to PCA, PCOORD performs an orthogonal decomposition of the data into uncorrelated axes that successfully account for the maximum amount of variance among samples. Correlations between eigenvector coefficients (the position of an individual along an axis) and the original interlandmark distances were calculated and explored to determine which linear distance measures along the negative and positive ends of each axis contribute most strongly to separating samples in high dimensional space. High positive correlations areassociated with relatively large linear distance measures, whereas high negative correlations are associated with relatively small linear distance measures (Richtsmeier et al., 1998).

\section{RESULTS}

Form analysis. Facial shape differences among samples based upon superimposition. The results of the PCA shape analysis and associated wireframes are shown in Figure 3. Figure $3 \mathrm{~A}$ depicts $\mathrm{PC} 1$ vs. PC2 and $85 \%$ confidence intervals for the DS and euploid samples. Together PC1 and PC2 explain $40.57 \%$ of the facial shape variance in the data sets. The DS and euploid samples overlap along PC1. The Tolteca figurine is outside of the $85 \%$ confidence interval for the euploid sample, but within the $85 \%$ confidence interval for the DS sample. The DS and euploid samples partially separate along PC2. Again the Tolteca figurine is just outside of the range of variation defined by the euploid sample and well within the range of facial variation defined by the DS sample. The shape and size of the $85 \%$ confidence ellipses for each sample suggest that there is a wider range of facial shape variation associated with the DS sample. PCA plots were also constructed based on biological sex and 4 year age groupings, but no differences among samples were found (results not shown). Figure 3C depicts directions of shape change associated with $\mathrm{PC} 1$ using a wireframe outline. The overall mean shape is shown in light grey. The mean shape changes associated with the positive end of PC1 are shown in black to illustrate the range of facial shape variation across the samples relative to the mean facial shape. PC1 is associated with differences in elevation of the eyes, the bridge of the nose, and the lateral and inferior margins of the lip. $\mathrm{PC} 1$ is also associated with changes in the width of the face and nose combined and slight changes in nose protrusion. Figure 3D depicts shape differences associated with PC2 such as changes in eye width and lateral placement of the corners of the eye. Moreover, PC2 includes differences in

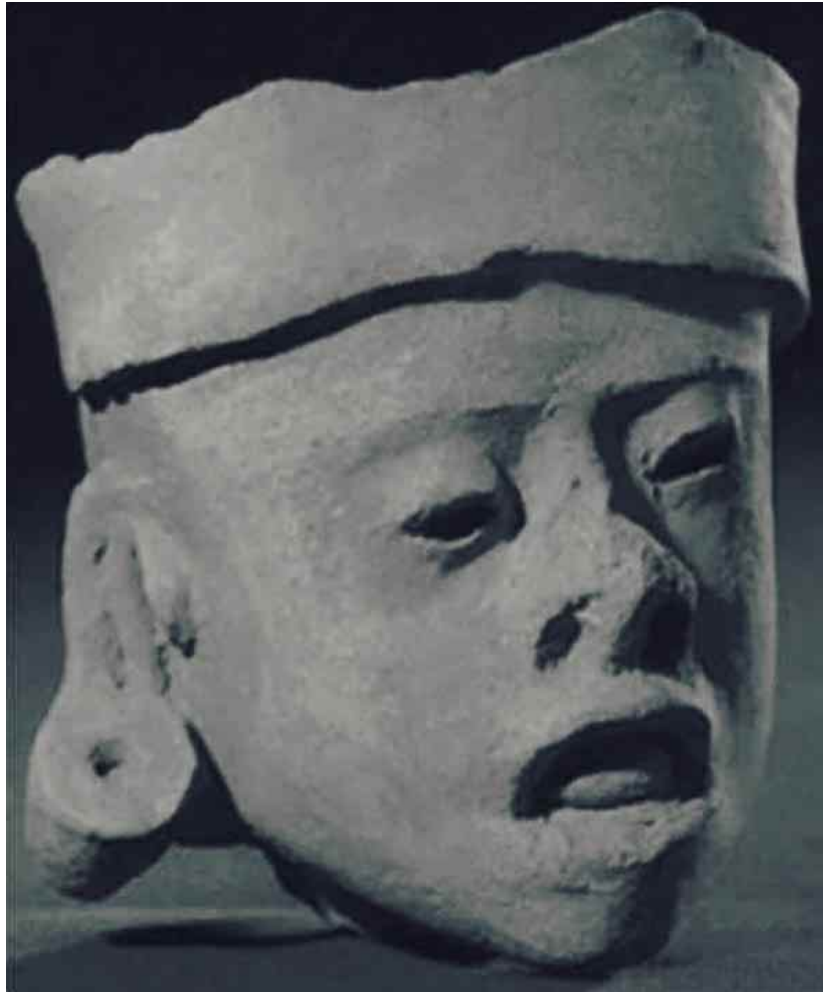

Fig. 1. Terra-Cotta Figurine from the Tolteca culture of Mexico (circa 500 A.D.) (Martinez-Frias, 2005).

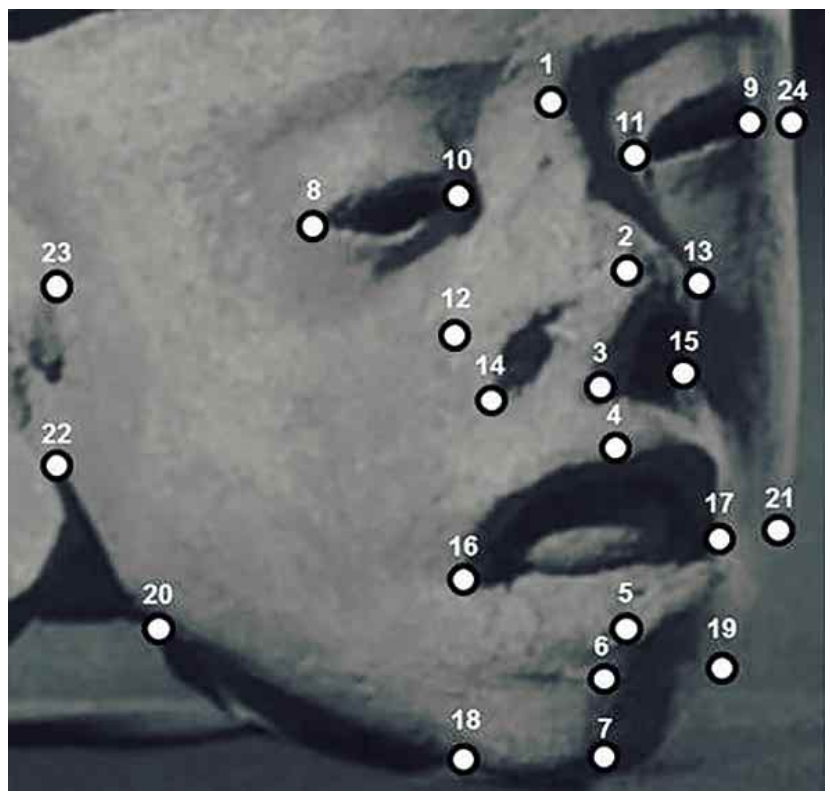

Fig. 2. Landmarks used in facial morphology analyses. Landmarks are defined in Table I.

elevation, protrusion, and width of the lower part of the nose around the nostrils and changes in lip height associated with the superior and inferior borders of the lip. Additionally, PC2 is associated with differences in facial width and the height and angle of the chin. 
Table I. Definitions of anatomical and constructed landmarks collected in this study. Midline and bilateral landmarks are depicted on the Tolteca figurine in Figure 2.

\begin{tabular}{|c|c|c|}
\hline & Landmark & Definition \\
\hline 1 & Nasion (n) & The point in the midline of both the nasal root and the nasofrontal suture. \\
\hline 2 & Pronasale (prn) & The most protruded point of the apex nasi. \\
\hline 3 & Subnasale (sn) & $\begin{array}{l}\text { The midpoint of the angle at the columella base where the lower border of the nasal } \\
\text { septum and the surface of the upper lip meet. }\end{array}$ \\
\hline 4 & Labrale Superius (ls) & $\begin{array}{l}\text { The midline soft-tissue point at labiale superius on the vermilion border of the } \\
\text { upper lip. }\end{array}$ \\
\hline 5 & Labrale Infe rius (li) & $\begin{array}{l}\text { The midline soft-tissue point at labiale inferius on the vermilion border of the } \\
\text { lower lip. }\end{array}$ \\
\hline 6 & Sublabiale ( $\mathrm{Sl})$ & The upper border of the chin along the midline. \\
\hline 7 & Menton (mtn) & The inferiormost border of the chin along the midline. \\
\hline $8(9)$ & Exocanthion (ex) & The point at the outer commissure of the eye fissure. \\
\hline $10(11)$ & Endocanthion (en) & The point at the inner commissure of the eye fissure. \\
\hline $12(13)$ & Alar curvature (ac) & The most lateral point in the curved base line of each ala. \\
\hline $14(15)$ & Subalare (sbal) & $\begin{array}{l}\text { The point at the lower limit of each alar base, where the alar base disappears into } \\
\text { the skin of the cutaneous upper lip. }\end{array}$ \\
\hline $16(17)$ & Chelion (ch) & $\begin{array}{l}\text { The point located at eash labial commissure at the most lateral intersection of the } \\
\text { upper and lower lip. }\end{array}$ \\
\hline $18(19)$ & Inferiolateral facial border (ifb) & $\begin{array}{l}\text { The inferior and lateral border of the chin directly inferior to the chelion } \\
\text { landmarks. }\end{array}$ \\
\hline $20(21)$ & Lateral facial border (lfb) & $\begin{array}{l}\text { The point on the cheek border of either side of the face that intersects with a line } \\
\text { passing through the left and right chelion landmarks. }\end{array}$ \\
\hline 22 & Otobasion inferius (obi) & $\begin{array}{l}\text { The point of the attachment of the ear lobe to the cheek that determines the lower } \\
\text { border of the ear insertion. }\end{array}$ \\
\hline $23(23)$ & Superiolateral facial border (sfb) & $\begin{array}{l}\text { The superior and lateral border of the sides of the face where a line passing through } \\
\text { the left and right endocanthion intersects with the sides of the face. }\end{array}$ \\
\hline
\end{tabular}

Figure 3B depicts PC2 vs. PC3 and 85\% confidence intervals for the DS and euploid samples. Together PC2 and PC3 explain $30.48 \%$ of the facial shape variance in the data sets. Again, the Tolteca figurine falls just outside of the $85 \%$ confidence interval for the euploid sample, but is situated well within the $85 \%$ confidence interval for the DS sample. Although both samples overlap along PC2 and PC3, the confidence ellipse for the DS sample is larger than the confidence ellipse of the euploid sample. Figure 3E depicts shape changes associated with PC3, which include small changes in eye elevation and width, and changes in the lateral and inferior margins of the lip. Moreover, PC3 includes changes in facial width and a more vertical facial profile. PC3 is also associated with changes in chin width and height, a more squared chin, and angular chin deviations.

Global facial dissimilarity among samples. An EDMA global test of similarity in facial form for the figurine and DS sample failed to reach statistical significance $(\mathrm{p}$-value $=$ 0.093), indicating that facial form between these two samples is similar. The global test of facial form for the figurine and euploid sample was significant ( $\mathrm{p}$-value $=0.032$ ), suggesting that facial morphology of the figurine differs from euploid facial morphology. The global comparison of DS and euploid facial morphology was also significant (p-value $\leq 0.001$ ), indicating that DS and euploid facial form is dissimilar.

Morphological measures that differ among samples. A PCOORD analysis was carried out to explore patterns of multivariate facial form variation and to localize facial linear distance measurements that differ most among samples. Figure 4A depicts PCOORD axes 1 and 2, which explain $36.65 \%$ of the variation across samples. The linear distances along the positive and negative axis that contribute most heavily to separation among the samples are depicted for each axis. Along PCOORD axis 1 the DS and euploid samples partially separate, but the Tolteca figurine is clearly within the rage of facial variation established for the DS sample and outside of the range of variation of the euploid sample. The linear distances along the negative end of axis 1 that best separate the DS and euploid sample consist of smaller measurements of the mid- and lower face in the DS sample. The linear distances along the positive end of axis 1 consist of larger lower face measurements related to facial width and lip width, and the width of the left eye in the euploid sample. Along axis 2 all samples overlap. The linear distances that best separate samples at the negative end of axis 2 are localized to the mid- and upper face and to 

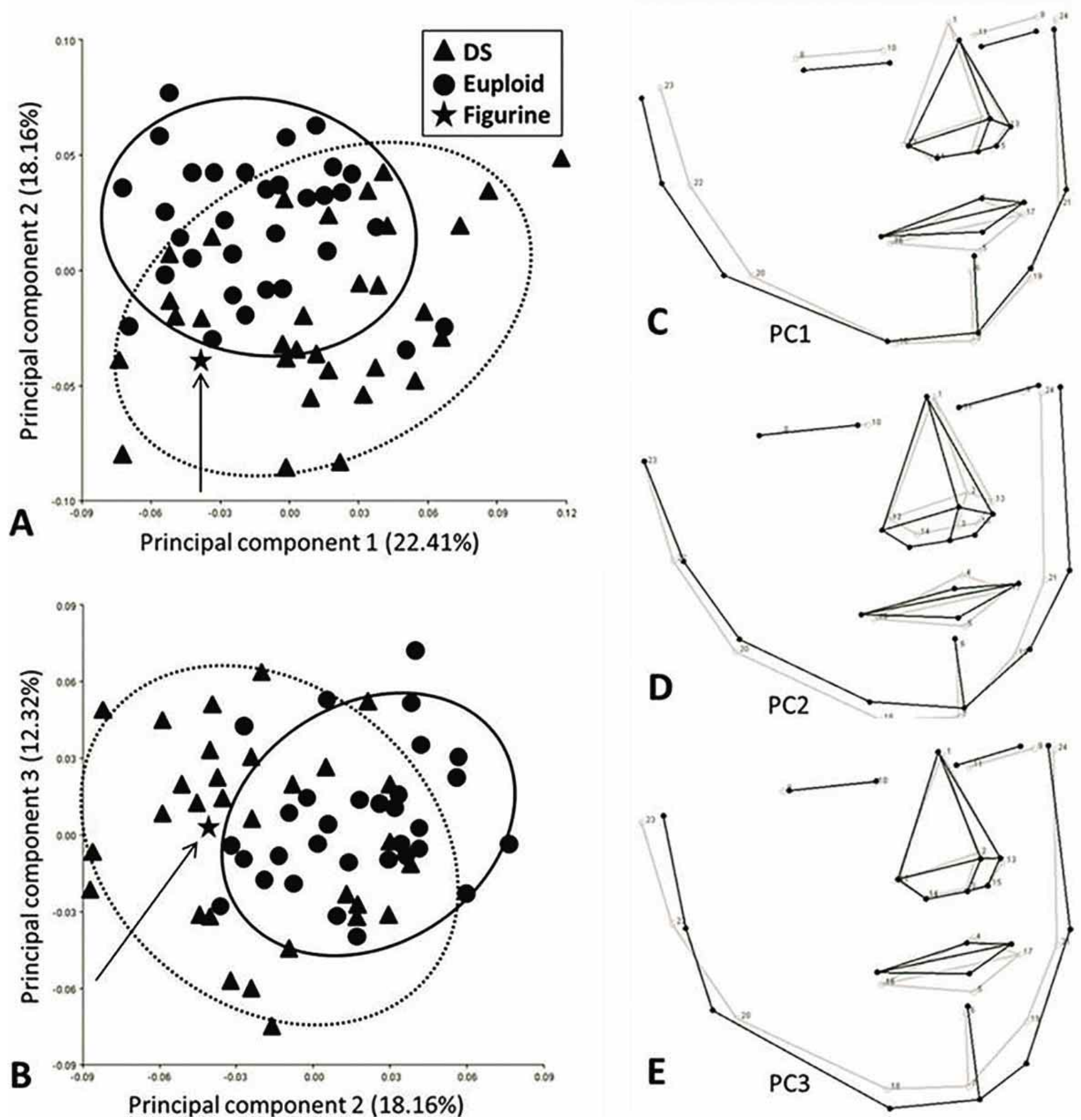

Fig. 3. Principal components analysis (PCA) results. PCs 1-3 explains 52.89\% of shape variation across samples. A) A plot of PC1 vs. PC2 is depicted for the DS (triangle) and euploid samples (circle) with $85 \%$ confidence ellipses. The Tolteca figurine is also plotted (star with arrow pointing to it) in relation to the trisomy 21 and euploid samples and falls outside of the confidence ellipse for euploid individuals, but within the confidence ellipse for the DS sample. B) A plot of PC2 vs. PC3 is depicted for each sample and the Tolteca figurine with $85 \%$ confidence ellipses. C) Shape changes associated with PC1, which explains $22.41 \%$ of shape variation across samples. The grey wireframe represents the average shape configuration along PC1, while the black wireframe represents the range of shape deviation from the mean shape along PC1. D) Shape changes associated with PC2, which explains $18.16 \%$ of shape variation across samples. E) Shape changes associated with PC3, which explains $12.32 \%$ of shape variation across samples. 
changes in orientation of the left eye. The linear distances that best separate samples at the positive end of axis 2 are localized to changes in width of the right half of the midface.

Figure 4B depicts principal coordinate axis 2 vs. axis 3, which explain $31.26 \%$ of the variation across samples. Along axis 3 the DS and euploid samples partially separate and the figurine is outside of the range of facial variation depicted for
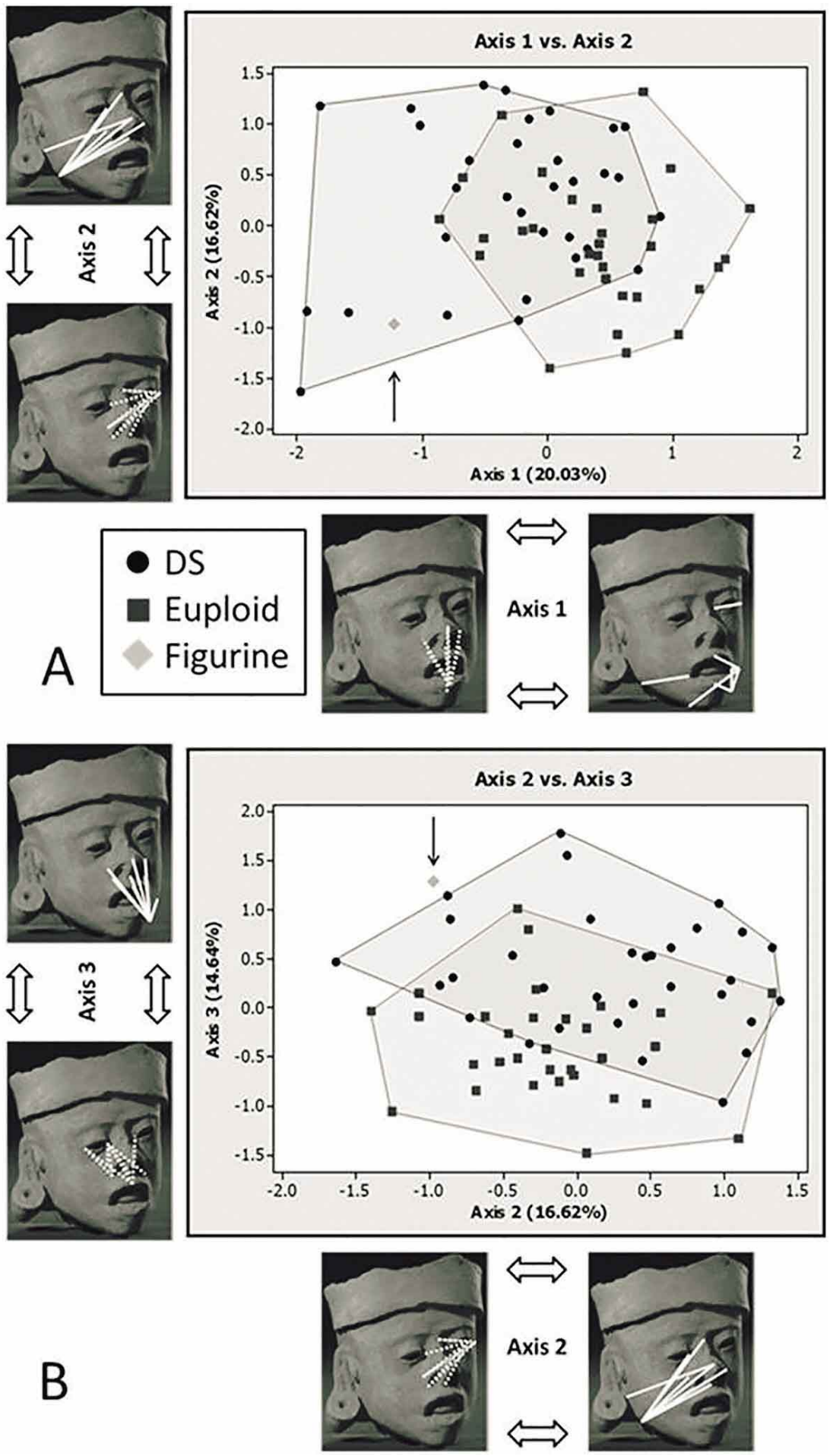

Axis 2 vs. Axis 3

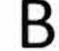

$B$ both the DS and the euploid samples; however, the Tolteca figurine is much closer to the DS sample than it is to the euploid sample. The linear distances that best separate samples at the negative end of axis 3 are localized to the midface and consist mostly of vertical facial measurements between the corners of the eye, the lower and lateral borders of the nose, and the upper lip. Along the positive end of axis 3 the linear distances that best separate the samples consist of several mid- and lower face measurements localized to the left inferiolateral facial border and different aspects of the upper lip and lower and lateral borders of the nose.

Fig. 4. Principal coordinates analysis results. Axes 1-3 explain $51.29 \%$ of the form variation across samples. A) A plot of axis 1 vs. axis 2 is depicted for the Down syndrome (DS) (circle) and euploid samples (square). The Tolteca figurine is shown (diamond with arrow pointing to it) in relation to the other samples and falls outside of the range defined for the euploid sample, but within the range of the DS sample. The linear distances that best separate samples are depicted for the negative (dotted lines) and positive (solid lines) ends of each axis. B) A plot of axis 2 vs. axis 3 is depicted for each sample and the Tolteca figurine. The Tolteca figurine is outside of the range defined for the DS and euploid samples, but closer to the range of the DS sample. 


\section{DISCUSSION}

It has been argued that the terra-cotta Tolteca figurine represents an individual with trisomy 21 because several qualitative facial features are present: palpebral fissures, oblique eyes, midfacial hypoplasia, and the open mouth frequently seen in DS individuals (Martinez-Frias; Starbuck). DS faces are frequently thought of as "characteristic" but factors such as genetic background, age, sex, environment, and altered growth patterns can affect the traits present in each individual DS face (Ferrario et al., 2004a, 2004b; Fink et al., 1975; Fischer-Brandies, 1986; Frostad; Starbuck et al., 2011). As a result, DS faces are variable, and many morphological forms can be associated with the "characteristic" DS face. Rather than relying on the presence or absence of qualitative traits that are "characteristic" of individuals with trisomy 21 , the quantitative results presented here capture the range of facial variation that can occur in DS and euploid faces due to differences in age, sex, and ethnic background.

Multivariate geometric morphometric techniques were employed throughout this study to determine if patterns of morphological variation associated with the Tolteca figurine are more consistent with a sample of DS faces or a sample of euploid faces. The DS and euploid samples in this study do not entirely separate in the multidimensional shapespace defined by a principal components analysis (PCA). However, results from the PCA analysis clearly depict the Tolteca figurine outside of the $85 \%$ confidence ellipses established for the euploid sample while simultaneously depicting the Tolteca figurine within the $85 \%$ confidence ellipses for the DS sample along PCA axes 1-3 (Fig. 3). The Tolteca figurine falls just outside of the range of variation defined for euploid faces along PC2, which does show partial separation between DS and euploid samples. This suggests that changes in facial shape variation associated with PC2 may be the main shape changes that distinguish the Tolteca figurine from the euploid sample. These changes include 1) mediolateral changes in eye width and width between the eyes, 2) anterioposterior changes in nasal protrusion and superioinferior displacement of the nasal wings and nostrils, possibly due to midfacial hypoplasia, 3) changes in the superioinferior location of the lip borders, possibly due to the open mouth posture frequently present in DS, and 4) changes in facial width, chin height, and the angle of the chin. The Tolteca figurine falls within the range of facial variation associated with $\mathrm{PC} 2$, but it lies more closely to the center of the DS distribution than some of the other DS individuals located on the fringes of the shapespace defined in Figure 3. Thus, the Tolteca figurine exhibits morphology that is more similar to average DS faces than to the extremes of facial morphology found in this sample of DS individuals. While the range of facial variation in DS has not been explored in detail, the size and shape of the PCA confidence ellipses indicate that DS faces exhibit a wider range of facial phenotypic variation than euploid faces (Fig. 3). Overall, quantitative PCA results support the argument that the Tolteca figurine likely depicts an individual with trisomy 21 .

EDMA form results suggest that the facial form of the Tolteca figurine is significantly different from the euploid sample (p-value 0.032). However, the facial form of the Tolteca figurine is not significantly different from the DS sample (p-value 0.093). The DS and euploid samples in this study do not entirely separate in the multidimensional formspace defined by a principal coordinates analysis (PCOORD), but there is partial separation of samples along axes 1 and 3. For axes 1 and 2 (Fig. 4) the Tolteca figurine clearly lies in the formspace defined for the DS sample and outside of the formspace defined for the euploid sample. The negative end of axis 1 is associated with smaller linear measures of the mid- and lower face around the nose and mouth in the DS sample, whereas the positive end of axis 1 is associated with larger linear measures of lower facial width and eye width in the euploid sample. The negative end of axis 2 is associated with smaller linear measures of the midand upper face in the DS and euploid samples around the left eye, whereas the positive end of axis 2 is associated with larger linear measures of midfacial width in the DS and euploid samples on the right side of the face. Axes 2 and 3 depict the Tolteca figurine outside of the range of the DS and euploid samples, but the Tolteca figurine is much closer to the range of variation established for the DS sample. The negative end of axis 3 is associated with smaller vertical measures of the midface in the euploid sample around the eyes, whereas the positive end of axis 3 is associated with larger linear distance measures of the mid- and lower face in the DS sample localized to the inferiolateral facial border, possibly due to an open mouthed facial posture. Taken together, results from the quantitative analyses presented here also support the argument that the Tolteca figurine exhibits facial morphology that is consistent with the facial variation found in a sample of DS individuals.

Arguments for or against a diagnosis of DS in different forms of material culture are often based on the assumption that characteristics commonly associated with trisomy 21 ought to be depicted in the artwork created. However, DS live-births are rare (approximately 1:700) and historically individuals with DS had a relative short average lifespan (9 years in 1900). When both of these factors are taken into account, it is likely that very few models with DS would have been available for an artist to depict 1500 years 
ago. The relative rarity of DS may have precluded many artists from ever meeting more than a few individuals with DS and possibly none at all, although through time as populations became sedentary and increasingly dense the likelihood of an artist encountering a DS individual probably increased.

Many characteristics are associated with the DS face, but individual DS faces are variable and not all traits associated with trisomy 21 are present in every individual DS face. Artists working with a DS model may have recreated the traits present in a particular individual without knowledge of the range of facial variation that can occur from trisomy 21. Thus, traits that are present or absent in a particular piece of material culture thought to depict an individual with DS may result from "artistic founder effects" that occur from recreating a single DS model in artwork or copying features from another artifact, rather than inattention to detail on the part of the artist (Starbuck, 2011). Other factors that may affect how accurately an individual with DS is portrayed in a particular piece of material culture include artistic skill level, cultural context and values, artistic expression (i.e. was the artist attempting to be realistic?), social structure, mythology or religion, and the materials available to create the artwork (e.g. clay, stone, paint) in a particular geographic region (Vegter \& Hage).

Unfortunately nothing is known about the artist or his or her intentions when creating this artifact over 1500 years ago. From an anthropological standpoint, the fact that this figurine was created suggests that the individual who stood as a model for the artist lived well into childhood and possibly adulthood. If correct, this could suggest that the Tolteca culture of Mexico did not practice infanticide of individuals with perceived deformities. Alternatively, it may be the case that the DS individual depicted was not perceived as being deformed and may have enjoyed an elevated status, possibly due to social class. Artifacts depicting various health conditions have been recovered in other cultures and in some cases are thought to have functioned as an offering to the gods to attain lasting health or to request cures for medical ailments (Pirsig et al.). Perhaps the artist who created the Tolteca figurine had a child or a sibling with DS and created this artifact with the hope of improving the DS individual's health. If true, the terra-cotta figurine may provide insight into ancient Tolteca religious practices. However, it will never be known if the artist who created this artifact intended for it to be a realistic portrayal of someone with trisomy 21. It is difficult to extrapolate cultural values, morals, and compassion from material culture due to a lack of evidence and because many assumptions would be required (Dettwyler, 1991). For example, if the Tolteca figurine was created to represent a living individual, we cannot assume that that individual was a burden or a nonproductive member of society. This individual may have played a vital role in his or her society. Nor can we assume that this individual was treated well or poorly because there is no evidence to support either argument. Fortunately, the quantitative analyses presented here require no such assumptions, and the results of these analyses strongly suggest that the figurine depicts an individual with DS. The methodology utilized in this study is objective and has the potential to be used for future investigations of material culture depicting craniofacial form to compliment, and possibly supersede, qualitative diagnoses of human conditions affecting the face.

\section{ACKNOWLEDGMENTS}

Grant sponsorship: Graduate Research Fellowship grant from the National Science Foundation; Grant number: DGE-053135 (to J.M.S.); Grant sponsor: Doctoral Dissertation Research Improvement Grant from the National Science Foundation; Grant number: BCS-1061563 (to J.M.S.).

STARBUCK, J. M. Evaluación cuantitativa de la morfología facial de una Figura Tolteca de México utilizando la morfometría geométrica. Int. J. Morphol., 32(2):499-509, 2014.

RESUMEN: Con el objetivo de evaluar cuantitativamente las complejas condiciones medicas craneofaciales, se pueden combinar los enfoques morfométricos con imágenes 2D o 3D representadas en la cultura material, para un mayor conocimiento referente al estudio cultural. Una figura de terracota (alrededor del 500 DC) de la cultura Tolteca de México ha sido previamente y cualitativamente "diagnosticada" con síndrome de Down (SD) en base a la presencia o ausencia de rasgos faciales típicamente asociados con trisomía 21. El propósito de esta investigación fue comprobar cuantitativamente la hipótesis de que esta figura de la cultura Tolteca exhibe rasgos faciales consistentes con SD. Se identificaron puntos de referencia similares $(n=24)$ según sexo y edad $(5-20$ años $)$ a imágenes faciales de individuos con SD $(n=32)$, individuos euploides $(n=32)$ y de la figura Tolteca. Los puntos de referencia fueron sometidos a un análisis morfométrico geométrico, y los resultados sugieren que la morfología facial de la figura Tolteca es consistente con el SD.

PALABRAS CLAVE: Trisoma 21; Síndrome de Down; 3dMD; Distancia euclidiana; Matriz de análisis (EDMA); Analisis principal de coordinadas. 


\section{REFERENCES}

Benda, C. E. Observations on the malformations of the head in Mongoloid deficiency. J. Pediatr., 19(6):800-16, 1941.

Bookstein, F. L. Morphometric tools for landmark data: geometry and biology. Cambridge, Cambridge University Press, 1991.

Bookstein, F. L. Biometrics, biomathematics and the morphometric synthesis. Bull. Math. Biol., 58(2):313-65, 1996.

Canalis, R. F. \& Cino, L. Ceramic representations of facial paralysis in ancient Peru. Otol. Neurotol., 24(5):828-31, 2003.

Centers for Disease Control and Prevention (CDCP). Improved national prevalence estimates for 18 selected major birth defects--United States, 1999-2001. MMWR Morb. Mortal Wkly. Rep., 54(51):1301-5, 2006.

Collmann, R. D. \& Stoller, A. A life table for mongols in Victoria, Australia. J. Ment. Defic. Res., 7:53-9, 1963.

Dettwyler, K. A. Can paleopathology provide evidence for "compassion"? Am. J. Phys. Anthropol., 84(4):375-84, 1991.

Diamandopoulos, A. A.; Rakatsanis, K. G. \& Diamantopoulos, N. A neolithic case of Down syndrome. J. Hist. Neurosci., 6(1):869, 1997.

Emery, A. E. Genetic disorders in portraits. Am. J. Med. Genet., 66(3):334-9, 1996.

Ferrario, V. F.; Dellavia, C.; Colombo, A. \& Sforza, C. Three-dimensional assessment of nose and lip morphology in subjects with down syndrome. Ann. Plast. Surg., 53(6):577-83, 2004a.

Ferrario, V. F.; Dellavia, C.; Zanotti, G. \& Sforza, C. Soft tissue facial anthropometry in Down syndrome subjects. J. Craniofac. Surg., 15(3):528-32, 2004b.

Fink, G. B.; Madaus, W. K. \& Walker, G. F. A quantitative study of the face in Down's syndrome. Am. J. Orthod., 67(5):540-53, 1975 .

Fischer-Brandies, H.; Schmid, R. G. \& Fischer-Brandies, E. Craniofacial development in patients with Down's syndrome from birth to 14 years of age. Eur. J. Orthod., 8(1):35-42, 1986.

Frostad, W. A.; Cleall, J. F. \& Melosky, L. C. Craniofacial Complex in the Trisomy 21 Syndrome (Down's Syndrome). Arch. Oral Biol., 16(7):707-22, 1971.

Greig, D. M. The skull of the mongolian imbecile. Edinburgh Med. J., 34:253-74, 1927a.

Greig, D. M. The skull of the mongolian imbecile. Edinburgh Med. J., 34:321-39, $1927 \mathrm{~b}$.
Ionita-Laza, I.; Rogers, A. J.; Lange, C.; Raby, B. A. \& Lee, C. Genetic association analysis of copy-number variation (CNV) in human disease pathogenesis. Genomics, 93(1):22-6, 2009.

Jones, R. The mouth in backward children (imbecile) of the mongolian type. Br. J. Psychiatry, 36:187-90, 1890.

Kisling, E. Cranial morphology in down's syndrome: a comparative roentgen-cephalometric study in adult males. Copenhagen, Royal Danish Dental College Copenhagen, 1966.

Klingenberg, C. P. \& McIntyre, G. S. Geometric morphometrics of developmental instability: analyzing patterns of fluctuating asymmetry with procrustes methods. Evolution, 52(5):1363$75,1998$.

Klingenberg, C. P. Morphometrics and the role of the phenotype in studies of the evolution of developmental mechanisms. Gene, 287(1-2):3-10, 2002.

Klingenberg, C. P. Morphometric integration and modularity in configurations of landmarks: tools for evaluating a priori hypotheses. Evol. Dev. 11(4):405-21, 2009.

Klingenberg, C. P. MorphoJ: an integrated software package for geometric morphometrics. Mol. Ecol. Resour. 11(2):353-7, 2011.

Klingenberg, C. P.; Barluenga, M. \& Meyer, A. Shape analysis of symmetric structures: quantifying variation among individuals and asymmetry. Evolution, 56(10):1909-20, 2002.

Korbel; J. O.; Tirosh-Wagner, T.; Urban. A. E.; Chen, X. N.; Kasowski, M.; Dai, L.; Grubert, F.; Erdman, C.; Gao, M. C.; Lange, K.; Sobel, E. M.; Barlow, G. M.; Aylsworth, A. S.; Carpenter, N. J.; Clark, R. D.; Cohen, M. Y.; Doran, E.; FalikZaccai, T.; Lewin, S. O.; Lott, I. T.; McGillivray, B. C.; Moeschler, J. B.; Pettenati, M. J.; Pueschel, S. M.; Rao, K. W.; Shaffer, L. G.; Shohat, M.; Van Riper, A. J.; Warburton, D.; Weissman, S.; Gerstein, M. B.; Snyder, M. \& Korenberg, J. R. The genetic architecture of Down syndrome phenotypes revealed by high-resolution analysis of human segmental trisomies. Proc. Natl. Acad. Sci. USA, 106(29):12031-6, 2009.

Kuppermann, M.; Learman, L. A.; Gates, E.; Gregorich, S. E.; Nease, R. F. Jr.; Lewis, J. \& Washington, A. E. Beyond race or ethnicity and socioeconomic status: predictors of prenatal testing for Down syndrome. Obstet. Gynecol., 107(5):1087-97, 2006.

Leamy, L. J. \& Klingenberg, C. P. The genetics and evolution of fluctuating asymmetry. Annu. Rev. Ecol. Evol. Syst. 36:1-21, 2005. 
LeJeune, J.; Gautier, M. \& Turpin, R. Etude des chromosomes somatiques de neuf enfants mongoliens. C. R. Hebd. Seances Acad. Sci., 248(11):1721-2, 1959.

Lele, S. R. \& Richtsmeier, J. T. An invariant approach to statistical analyses of shape. New York, Chapman and Hall/CRC, 2001.

Makino, T. \& McLysaght, A. Ohnologs in the human genome are dosage balanced and frequently associated with disease. Proc. Natl. Acad. Sci. USA, 107(20):9270-4, 2010.

Martinez-Frias, M. L. The real earliest historical evidence of Down syndrome. Am. J. Med. Genet. A, 132A(2):231, 2005.

Megarbane, A.; Ravel, A.; Mircher, C.; Sturtz, F.; Grattau, Y.; Rethoré, M. O.; Delabar, J. M. \& Mobley, W. C. The 50th anniversary of the discovery of trisomy 21: the past, present, and future of research and treatment of Down syndrome. Genet. Med., 11(9):611-6, 2009.

Mitteroecker, P. \& Bookstein, F. The conceptual and statistical relationship between modularity and morphological integration. Syst. Biol., 56(5):818-36, 2007.

O'Riordan, M. W. \& Walker, G. F. Dimensional and proportional characteristics of the face in Down's syndrome. J. Dent. Handicap., 4(1):6-9, 1978.

Oliver, C. A. A clinical study of the ocular symptoms found in the so-called mongolian type of idiocy. Trans. Am. Ophthalmol. Soc., 6:140-8, 1891.

Pirsig, W.; Helidonis, E. \& Velegrakis, G. Medicine and art: facial palsy depicted in archaic Greek art on Crete. Am. J. Otolaryngol., 16(2):141-2, 1995.

Richtsmeier, J. T. \& Lele, S. A coordinate-free approach to the analysis of growth patterns: models and theoretical considerations. Biol. Rev. Camb. Philos. Soc., 68(3):381-411, 1993.

Richtsmeier, J. T.; Baxter, L. L. \& Reeves, R. H. Parallels of craniofacial maldevelopment in Down syndrome and Ts65Dn mice. Dev. Dyn.,217(2):137-45, 2000.

Richtsmeier, J. T.; Cole, T. M. 3rd; Krovitz, G.; Valeri, C.J. \& Lele, S. Preoperative morphology and development in sagittal synostosis. J. Craniofac. Genet. Dev. Biol., 18(2):64-78, 1998.

Richtsmeier, J. T.; DeLeon, V. B. \& Lele, S. R. The promise of geometric morphometrics. Am. J. Phys. Anthropol., 35:63-91, 2002.

Salter, V. \& Ramachandran, M. Medical conditions in works of art. Br. J. Hosp. Med. (Lond), 69(2):91-4, 2008.

Shaner, D. J.; Peterson, A. E.; Beattie, O. B. \& Bamforth, J.S. Soft tissue facial resemblance in families and syndrome-affected individuals. Am. J. Med. Genet., 102(4):330-41, 2001.
Shuttleworth, G. E. Clinical Lecture on Idiocy and Imbecility. Br. Med. J., 1(1309):183-6, 1886.

Starbuck, J. On the antiquity of trisomy 21: moving towards a quantitative diagnosis of Down syndrome in historic material culture. J. Contemp. Anthropol., 2(1):19-44, 2011.

Starbuck, J.; Reeves, R. H. \& Richtsmeier, J. Morphological integration of soft-tissue facial morphology in Down Syndrome and siblings. Am. J. Phys. Anthropol., 146(4):560-8, 2011.

Vegter, F. \& Hage, J. J. Clinical anthropometry and canons of the face in historical perspective. Plast. Reconstr. Surg., 106(5):1090-6, 2000.

Walker, P.L.; Cook, D. C.; Ward, R.; Braunstein, E. \& Davee, M. A Down Syndrome-like Congenital Disorder in a Prehistoric California Indian. Am. J. Phys. Anthropol., 34(Suppl. 12):179, 1991.

\section{Correspondence to:} John Marlow Starbuck, PhD

Department of Orthodontics and Facial Genetics IU School of Dentistry 1121 W. Michigan St. DS 270A Indianapolis, IN 46202 UNITED STATES

Email: jstarbuc@iu.edu

Received: 09-12-2013

Accepted: 15-01-2014 